\title{
HILIRISASI SARANG LEBAH MADU MENJADI PRODUK LILIN AROMATERAPI BAGI MASYARAKAT PETANI LEBAH MADU
}

\author{
Fatimah, Dwi Sandri \\ Jurusan Teknologi Industri Pertanian, Politeknik Negeri Tanah Laut \\ Jl. A. Yani, Km 6, Ds. Panggung, kec. Pelaihari, kab Tanah Laut, \\ Kalimantan Selatan \\ *Korespondensi penulis, email: fatimah@ politala.ac.id
}

\begin{abstract}
Abstrak: Madu merupakan salah satu hasil hutan bukan kayu (HHBK) unggulan di Kabupaten Tanah Laut. Pada pengambilan hasil madu, sarangnya tidak dimanfaatkan lebih lanjut oleh para peternak lebah. Lilin yang berasal dari sarang lebah hanya dimanfaatkan untuk pembuatan pondasi rumah untuk sarang lebah. Dengan kata lain, lilin lebah yang dihasilkan belum menghasilkan nilai ekonomi yang lebih. Lilin lebah dapat lebih bernilai ekonomis dengan membuat produk yang bernilai jual tinggi, salah satunya adalah dengan membuat produk lilin aromaterapi. Masyarakat sasaran pada kegiatan ini adalah Petani lebah madu Kelompok Tani Harapan Makmur dan Kelompok Wanita Tani Mekar Sari. Lingkup kegiatan meliputi pengambilan lilin lebah dari sarang lebah kemudian membuat lilin aromaterapi dari lilin lebah yang dihasilkan dengan menambahkan aroma minyak atsiri, sehingga dihasilkan lilin aromaterapi dari lilin lebah. Lilin aromaterapi yang terbuat dari lilin lebah menghasilkan aroma sesuai dengan minyak atsiri yang digunakan ketika dinyalakan.
\end{abstract}

Kata Kunci: Sarang lebah, Lebah madu, Lilin aroma terapi.

\section{PENDAHULUAN}

Pendahuluan Budidaya lebah madu di Kabupaten Tanah Laut berpotensi positif untuk di kembangkan di wilayah ini karena di dukung oleh pakan lebah madu yang banyak. Madu merupakan salah satu hasil hutan bukan kayu (HHBK) unggulan di Kabupaten Tanah Laut yang ditetapkan melalui Keputusan Bupati Tanah Laut Nomor 188.45/463-KUM/2013 tanggal 10 September 2013 tentang Penetapan Jenis Hutan Bukan Kayu Unggulan Kabupaten Tanah Laut yaitu Lebah Madu, Gaharu, dan Nipah. Pada pengambilan madu madu, sarangnya tidak dimanfaatkan lebih lanjut oleh para peternak lebah. Lilin yang berasal dari sarang lebah tersebut hanya dimanfaatkan untuk pembuatan pondasi rumah untuk sarang lebah. Dengan kata lain, lilin lebah yang dihasilkan belum menghasilkan nilai ekonomi yang lebih.

Lilin lebah adalah bahan yang digunakan dalam pembuatan lilin merupakan bahan yang dapat diperbarui dan aman bagi kesehatan, sedangkan bahan lilin/parafin dari sumber minyak bumi merupakan bahan baku yang tidak dapat diperbarui. Lilin lebah akan lebih bernilai ekonomis dengan membuat produk yang bernilai jual tinggi, salah satunya adalah dengan membuat produk lilin aromaterapi. 
Penggunaan minyak atsiri dalam berbagai macam produk rumah tangga, seperti untuk desinfektan, penyegar ruangan, pewangi pakaian, dan untuk aromaterapi. Pemanfaatan minyak atsiri menjadi lilin aromaterapi berpotensi besar untuk dijadikan usaha, hal ini terkait dengan tuntutan hidup yang semakin besar yang mendorong setiap orang bekerja keras sehingga menimbulkan rasa lelah dengan berwisata relaksasi lilin aromaterapi dapat memberikan ketenangan.

Identifikasi permasalahan telah dilakukan langsung ke kelompok tani Wanita Tani Mekar Sari dan Kelompok Tani Harapan Makmur oleh Fatimah, dkk (2016). Permasalahan yang dihadapi mitra kelompok tani sangat kompleks, mulai dari budidaya sampai tahap akhir pemasaran. Untuk menangani permasalahan tersebut diupayakan penyelesaian secara bertahap dan berkesinambungan. Peran berbagai pihak sangat diperlukan dalam penyelesaian masalah yang dihadapi. Salah satu peran perguruan tinggi, dalam hal ini Politeknik Negeri Tanah Laut yang berada di kabupaten Tanah Laut adalah dengan memanfaatkan sarang lebah madu yang tidak digunakan dijadikan produk lilin aromaterapi yang memiliki nilai jual lebih tinggi.
Kegiatan ini dilakukan sebagai sarana menerapkan pengetahuan yang dimiliki dosen kepada masyarakat Petani lebah madu, khususnya kelompok tani Wanita Tani Mekar Sari dan Kelompok Tani Harapan Makmur yang ada di kabupaten Tanah Laut. Tujuan kegiatan ini agar masyarakat mengetahui cara pengambilan lilin dari sarang lebah kemudian dilanjutkan dengan membuat lilin aromaterapi dengan menambahkan minyak aromaterapi. Manfaat kegiatan ini yaitu agar dapat dijadikan salah satu peluang usaha baru dalam pembuatan produk dari sarang lebah madu menjadi lilin aromaterapi.

\section{METODE PELAKSANAAN}

Lingkup kegiatan pengabdian kepada masyarakat meliputi penyuluhan tentang cara pengambilan lilin dari sarang dan penggunaan lilin lebah dalam pembuatan lilin aromaterapi dan mengajarkan kepada masyarakat cara membuat produk lilin aromaterapi dari sarang lebah. Luaran yang dihasilkan dari kegiatan pengabdian kepada masyarakat berupa produk lilin aromaterapi.

\section{Kelompok Sasaran}

Mitra yang akan menjadi sasaran untuk program kegiatan pengabdian ini adalah Kelompok Wanita Tani Mekar Sari yang diketuai oleh Siti Maysaroh dan 
Kelompok Tani Harapan Makmur yang diketuai oleh Hardjono di desa Karang Taruna. Budidaya lebah madu dilakukan secara berkelompok, artinya di daerah tersebut ada beberapa orang yang beternak lebah madu. Jumlah stup/kotak sarang lebah di desa Karang Taruna berjumlah 55 kotak dengan jumlah produksi madu sebanyak $55 \mathrm{~kg} / \mathrm{bulan}$ (Dinas Kehutanan Kabupaten Tanah Laut, 2014). Sarang lebah madu dihasilkan dari proses se telah pengambilan madu yang yang dilakukan secara sederhana.

\section{Alat dan Bahan}

Alat yang digunakan adalah pelatan gelas standar, pisau, kompor, cetakan dan saringan. Sedangkan bahan yang digunakan adalah sarang lebah, sumbu lilin, dan minyak atsiri aroma kenanga, lavender, dan mawar.

\section{Prosedur Kerja Pengambilan Lilin}

\section{Lebah}

Mitra diberi pengetahuan cara ekstraksi lilin lebah dan cara membuat lilin. Lilin lebah madu diperoleh dari proses pemanasan sarang lebah madu. Sarang lebah dipanaskan pada suhu $65^{\circ} \mathrm{C}$ hingga ada cairan yang meleleh, kemudian dipisahkan kotoran dan cairan lilin. Cairan lilin murni dipanaskan lagi dengan suhu $90^{\circ} \mathrm{C}$ dan dinginkan sehingga diperoleh lilin murni. Untuk membuat lilin lebah sebanyak 100 gram diperlukan sarang lebah sekitar 300 gram

\section{Pembuatan Lilin Aromaterapi}

Lilin aromaterapi merupakan lanjutan pengolahan dari lilin. Lilin aromaterapi dibuat dengan menambahkan bahan minyak atsiri pada lilin lebah. Ditimbang lilin lebah sebanyak 15 gram, kemudian dipanaskan lilin dengan suhu $70-85^{\circ} \mathrm{C}$, diturunkan suhu $60-65^{\circ} \mathrm{C}$ sambil dicampur dengan minyak atsiri (minyak sereh, mawar dan lain-lain) dan diaduk hingga merata. Campuran kemudian dituang ke cetakan sambil ditambahkan dengan sumbu untuk menyalakan lilin. Setelah itu didiamkan sekitar 2 jam agar lilin menjadi keras dan didapatkan lilin aromaterapi.

\section{PEMBAHASAN}

Pengabdian kepada masyarakat dilaksanakan di desa Karang Karuna bersama Kelompok Wanita Tani Mekar Sari dan Kelompok Tani Harapan Makmur, yang mana salah satu kegiatan kelompok tani ini membudidayakan lebah madu. Sarang lebah madu setelah dipanen digunakan sebagai bahan dasar pada pembuatan produk lilin aromaterapi. Tahapan awal dimulai dengan penyluhan kepada masyarakat tentang pemanfaatan 
sarang lebah (Gambar1). Sarang lebah akan lebih bernilai ekonomis jika diolah menjadi produk yang bernilai jual tinggi. Tahapan berikutnya adalah praktik langsung teknik pengambilan lilin dari sarang lebah (Gambar 2). Lilin yang dihasilkan langsung diolah menjadi produk lilin aromaterapi, diantaranya lilin aromaterapi yang bisa dinyalakan (Gambar 3b) dan lilin aromaterapi dalam bentuk bunga hias (Gambar 3c).



Gambar 1. Penyuluhan pemanfaatan sarang lebah madu

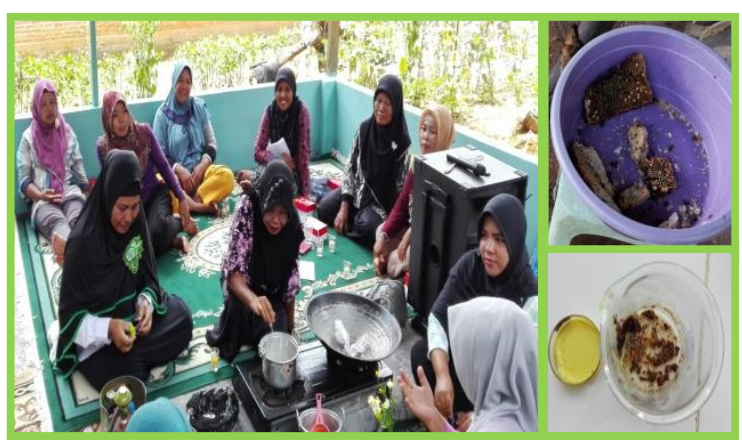

Gambar 2. Pelatihan pengambilan lilin



a

b

c
Gambar 3.

a. Pelatihan pembuatan lilin lebah aroma terapi.

b. Lilin aromaterapi

c. Bunga hias lilin

aromaterapi

Kegiatan pengabdian ini mengajarkan langsung kepada masyarakat tentang pengambilan lilin lebah dari sarang lebah. Lilin atau dikenal juga dengan sebutan wax merupakan golongan lipid (lemak) yang berwujud padat pada suhu ruang. Ketika dilakukan pemanasan, maka lilin akan mencair dan terpisah dengan bagian bukan lilin dari sarang lebah. Metode pengambilan lilin ini beraneka ragam. Cara pemanasan langsung maupun menggunakan media air untuk pemanasan. Pemisahan antara lilin dan bagian lilin dapat dilakukan dengan penyaringan. Jika menggunakan media air, maka lilin akan mengapung diatas air. Jika air mulai agak dingin, maka lilin

berubah menjadi padatan, setelah itu dapat langsung diambil bagian lilinnya.

Lilin aromaterapi merupakan produk olahan dari lilin lebah dicampurkan dengan minyak aromaterapi/atsiri. Lilin aromaterapi dibuat untuk meningkatkan nilai jual dari lilin lebah, dimana sebelumnya hanya dibuang atau sebagian dimanfaatkan oleh Petani lebah sebagai pondasi sarang. Sebelum pembuatan lilin aromaterapi, diawali dengan penyuluhan 
tentang lilin lebah dan pemanfaatannya. Agar pembuatan lilin aromaterapi dapat diaplikasikan oleh masyarakat, untuk itu dilakukan analisis kelayakan usaha dari lilin aromaterapi. Berikut analisis usaha lilin aromaterapi skala rumah tangga (Tabel 1)

Tabel 1. Analisis Usaha Pembuatan Lilin Aromaterapi

\begin{tabular}{|c|l|c|l|l|l|}
\hline No & $\begin{array}{l}\text { Bahan } \\
\text { Pembuatan Sabun }\end{array}$ & Volume & Satuan & Harga Satuan & Jumlah \\
\hline 1 & Lilin lebah & 1000 & $\mathrm{~g}$ & $\mathrm{Rp} 175,000.00$ & $\mathrm{Rp} 175,000.00$ \\
\hline 2 & $\begin{array}{l}\text { Minyak } \\
\text { aromaterapi/atsiri }\end{array}$ & 50 & $\mathrm{ml}$ & $\mathrm{Rp} \mathrm{3,000.00}$ & $\mathrm{Rp} 150,000.00$ \\
\hline 3 & Sumbu & 1 & $\mathrm{rol}$ & $\mathrm{Rp} \mathrm{5,000.00}$ & $\mathrm{Rp} \mathrm{5,000.00}$ \\
\hline 4 & Gelas & 50 & $\mathrm{buah}$ & $\mathrm{Rp} \mathrm{5,000.00}$ & $\mathrm{Rp250,000.00}$ \\
\hline 5 & $\begin{array}{l}\text { Pemakaian } \\
\text { Kompor }\end{array}$ & 1 & $\mathrm{kali}$ & $\mathrm{Rp} \mathrm{1,000.00}$ & $\mathrm{Rp} 1,000.00$ \\
\hline 6 & Panci/wajan & 1 & $\mathrm{kali}$ & $\mathrm{Rp} \mathrm{1,000.00}$ & $\mathrm{Rp} 1,000.00$ \\
\hline 7 & Pengaduk & 1 & $\mathrm{kali}$ & $\mathrm{Rp} \mathrm{500.00}$ & $\mathrm{Rp} 500.00$ \\
\hline 8 & Biaya promosi & 1 & $\mathrm{kali}$ & $\mathrm{Rp} \mathrm{1,000.00}$ & $\mathrm{Rp} 1,000.00$ \\
\hline 9 & Bahan bakar dll & 1 & $\mathrm{kali}$ & $\mathrm{Rp} \mathrm{2,000.00}$ & $\mathrm{Rp} \mathrm{2,000.00}$ \\
\hline 10 & Tenaga kerja & 1 & $\mathrm{kali}$ & $\mathrm{Rp} 20,000.00$ & $\mathrm{Rp} \mathrm{20,000.00}$ \\
\hline & & & & & $\mathrm{Rp605,500.00}$ \\
\hline
\end{tabular}

Dari bahan diatas didapatkan lilin aromaterapi sebanyak 50 buah. Dengan demikian, harga pokok produksi (HPP) adalah :

$\mathrm{HPP}=\mathrm{Rp} .605,500,-$ / $50 \mathrm{biji}$

$$
=\mathrm{Rp} .12,110 / \mathrm{biji}
$$

Harga penjualan dapat dinaikkan menjadi Rp. 20.000/biji. Harga tersebut berpatokan pada harga lilin aromaterapi yang biasa dijual di pasaran, sehingga keuntungan yang diperoleh
Laba $=$ harga jual - HPP

$$
\begin{aligned}
& =20,000-12,110 \\
& =7890
\end{aligned}
$$

Keuntungan yang diperoleh sebesar $\mathrm{Rp}$ 7,890.00 / unit. Dalam 1 kali produksi dapat memperoleh keuntungan sebesar

(50 x 7890) Rp. 394,500.00 dan

Profit margin usaha

$$
=(7890 / 12110) \times 100 \%=65 \%
$$

Pemasaran merupakan hal yang penting dilakukan mengingat lilin aromaterapi merupakan masih kebutuhan sekunder masyarakat bahkan tersier. Lilin aromaterapi masih kebutuhan sebagian masyarakat menengah keatas dan biasanya juga pada salon kecantikan. Perlu dilakukan usaha lainnya untuk meningkatkan promosi produk agar lilin aromaterapi sebagai produk keseharian yang aman dan bermanfaat bagi kesehatan.

\section{KESIMPULAN}

Kesimpulan dari kegiatan pengabdian kepada masyarakat bahwa sarang lebah menghasilkan lilin yang dapat dijadikan produk lilin aromaterapi. Produk lilin aromaterapi layak dijadikan sebagai salah satu wirausaha dengan profit margin sebesar $65 \%$. 


\section{UCAPAN TERIMA KASIH}

Ucapan terima kasih disampaikan kepada

Direktorat Riset dan Pengabdian Masyarakat Kementerian Riset Teknologi, dan Pendidikan Tinggi atas bantuan dana kegiatan pengabdian kepada masyarakat melalui dana skema Ipteks bagi Masyarakat (IbM) tahun 2016.

\section{DAFTAR PUSTAKA}

Dinas Kehutanan Kabupaten Tanah Laut. 2014. Program Unggulan Kabupaten Tanah Laut "Tala Be Madu.

Fatimah, Sandri D., Nuryati. 2016. Pembuatan Sabun Madu bagi Masyarakat Petani Lebah Madu. Jurnal Pengabdian kepada Masyarakat. Volume 1 Nomor 1.



